\title{
緔irestice
}

\section{Protótipo de curso EaD online sobre anomalias craniofaciais para cirurgiōes-dentistas da atenção primária}

\author{
ONLINE EAD COURSE PROTOTYPE ON CRANIOFACIAL ANOMALIES FOR PRIMARY \\ ATTENTION DENTAL SURGEONS
}

Cínthia Ferreira Alves' , Edilma da Cruz Cavalcante ${ }^{2}$, Erivelton Pinto Coutinho ${ }^{3}$, Amanda Almeida de Oliveira ${ }^{4}$, Manoela Almeida Santos da Figueira ${ }^{5}$, Rui Manuel Rodrigues Pereira ${ }^{6}$

\footnotetext{
1 Residente de Odontologia em Saúde Coletiva. Programa de Residência em Saúde, Secretaria de Saúde do Recife - SESAU.

ORCID: https://orcid.org/0000-0003-2804-7831 Email: cfa512@hotmail.com

2 Residente de Odontologia em Saúde Coletiva. Programa de Residência em Saúde, Secretaria de Saúde do Recife - SESAU.

ORCID: https://orcid.org/0000-0003-0486-3471

Email: edilmadacruz.odontologia@gmail.com

${ }^{3}$ Residente de Odontologia em Saúde Coletiva.

Programa de Residência em Saúde, Secretaria de Saúde do Recife - SESAU.

ORCID: https://orcid.org/0000-0002-3044-4230

Email: coutinhoerivelton@hotmail.com

${ }^{4}$ Doutora em Educação em Ciências: química e saúde. Instituto de Medicina Integral Professor Fernando Figueira - IMIP.

ORCID: https://orcid.org/0000-0003-3278-3436

Email: mandafono@hotmail.com

5 Doutora em Odontologia. Instituto de Medicina Integral Professor Fernando Figueira - IMIP ORCID: https://orcid.org/0000-0001-5330-8314

Email: manufigueira@hotmail.com

- Doutor em Clínica Cirúrgica. Instituto de Medicina Integral Professor Fernando Figueira - IMIP.

ORCID: https://orcid.org/0000-0002-3317-0618

Email: ruipereira@realplastica.med.br
}

Correspondência: Instituto de Medicina Integral Professor Fernando Figueira - IMIP - Departamento: CADEFI. Rua dos Coelhos, n.300, Boa Vista, Recife-PE. Brasil. CEP: 50070-902.

Copyright: Esta obra está licenciada com uma Licença Creative Commons Atribuição-Não Comercial 4.0 Internacional.

Conflito de interesses: os autores declaram que não há conflito de interesses.

\section{Como citar este artigo}

Alves CF; Cavalcante E da C; Coutinho EP; Oliveira AA de; Figueira MAS da; Pereira MR. Protótipo de curso EaD sobre anomalias craniofaciais para cirurgiões-dentistas da atenção primária. Revista de Saúde Digital e Tecnologias Educacionais. [online], volume 5, n. 3. Editor responsável: Luiz Roberto de Oliveira. Fortaleza, dezembro de 2020, p. 01-16. Disponível em: http://periodicos.ufc.br/resdite/index. Acesso em "dia/mês/ano".

Data de recebimento do artigo: 09/03/2020

Data de aprovação do artigo: 31/08/2020

Data de publicação: 31/12/2020

\section{Resumo}

Introdução: As anomalias craniofaciais não constam como prioritárias nas linhas de cuidado da atenção primária e seu tratamento é oferecido em centros de referência especializados. Contudo, há a necessidade de formação para que cirurgiões-dentistas estejam aptos a realizar $o$ atendimento e o acompanhamento odontológico do indivíduo com a anomalia craniofacial, reduzindo seu 
itinerário terapêutico. Corroborando com a proposta de Educação permanente no SUS, optou-se pela modalidade $\mathrm{EaD}$ online para qualificação profissional de forma indissociada de sua prática sem limitações de tempo e espaço. Objetivo: descrever o processo de desenvolvimento de um curso a distância sobre anomalias craniofaciais para cirurgiõesdentistas da atenção primária. Métodos: Foi adotada a terceira etapa (fase de desenvolvimento) do modelo ADDIE. A etapa de elaboração envolveu o momento da definição, das estratégias de ensino, dos recursos didáticos, das ferramentas e tecnologias e das modalidades de avaliação. Resultados: Foram obtidos, como produtos do estudo, o plano de ensino e o guia do curso. Cada etapa da elaboração dos produtos foi discutida com a literatura pertinente, potencializando os aspectos pedagógicos do curso. Conclusão: 0 protótipo do curso seguiu padrões da literatura para estruturação de curso EaD, viabilizando potencial pedagógico adequado à realidade dos cursistas do público-alvo.

Palavras-chave: Anomalias craniofaciais, Educação em Saúde, Estratégias em Saúde, Educação a distância.

\section{Abstract}

Introduction: Craniofacial anomalies are not priorities in primary care and their treatment is offered in specialized reference centers. There are, however, the demand on training in order to dentists became able to provide dental care and follow-up for individuals with craniofacial anomalies, reducing individual therapeutic itinerary. Corroborating with Permanent Education in SUS, it was opted for the online distance education modality for professional qualification in an inseparable way from their practice without time and space limitations. Objective: to describe the process of developing a distance course on craniofacial anomalies for dentists in primary care. Methods: The third stage (development phase) of the ADDIE model was adopted. The elaboration stage involved the definition, teaching strategies, didactic resources, tools and technologies and assessment modalities. Results: The study plan and the course guide were obtained as products of the study. Each stage of product preparation was discussed with the relevant literature, enhancing the pedagogical aspects of the course. Conclusion: The course prototype followed standards in the literature for structuring distance education courses, enabling pedagogical potential appropriate to the reality of course participants in the target audience.

Keywords: Craniofacial anomalies, Health Education, Health Strategies, Distance Education.

\section{Introdução}

As anomalias craniofaciais constituem, entre as más formações congênitas, um grupo diverso e complexo. A designação comum de anomalias craniofaciais inclui anomalias isoladas e múltiplas de etiologia genética ou não. Via de regra, refere-se à situação em que os arcabouços cranianos e/ou faciais apresentam alterações de contorno. Elas, geralmente, demandam assistência multiprofissional, integral e especializada, cujo custo é elevado ${ }^{1,2,3}$.

Dentre as anomalias craniofaciais, a fissura de lábio e/ou palato é considerada a mais frequente. Afeta o lábio, o rebordo alveolar e/ou o palato e, quando não tratada, implica comprometimentos estéticos, funcionais e psicossociais, além de afetar as interações sociais. A deformidade dentofacial, como a deficiência maxilar anteroposterior, pode ser 
desenvolvida e, deste modo, interferir na aceitação de si próprio, podendo resultar em impacto negativo quanto à integração do indivíduo na sociedade 4 .

Existem intervenções para o enfrentamento deste problema no mundo e são realizadas em centros especializados ou hospitais públicos e privados, a depender da política de saúde de cada país ${ }^{5,6}$. Embora haja a necessidade de uma intervenção multidisciplinar, procedimentos de baixa complexidade podem e devem ser realizados na atenção primária, reduzindo o itinerário terapêutico, como no caso da assistência odontológica?.

Em todo o mundo, ainda persistem grandes incertezas e controvérsias em relação às melhores condutas clínicas e cirúrgicas no acompanhamento dos indivíduos com más formações craniofaciais ${ }^{3}$. No ano de 2017, Almeida et al. $^{8}$ realizaram um estudo com modelização de centros de referência, indicando a necessidade de capacitação de membros da equipe e de instrução aos usuários e familiares. Corroborando com essa proposta, Mendes et al. ${ }^{7}$ relataram que mesmo com a ausência de conhecimento sobre as anomalias craniofaciais, os profissionais conseguiram executar os procedimentos clínicos odontológicos básicos em pacientes com más formações. Porém, esses autores ${ }^{7}$ enfatizaram a importância de cursos de atualizações para os cirurgiões-dentistas a fim de uma melhor qualidade no atendimento, incluindo orientações aos pais no cuidado da higiene bucal na região de fissuras, aconselhamento alimentar e informações sobre o processo de reabilitação.

A proposta de Almeida et al. ${ }^{8}$ que institui qualidade para um centro de referência, incluindo estratégias de formação, está coerente com a Política Nacional de Educação Permanente ${ }^{9}$. Com a finalidade de manter os profissionais de saúde atualizados dentro do serviço público, no Sistema Único de Saúde (SUS), foi desenvolvida a Política Nacional de Educação Permanente em Saúde (PNEPS) no ano de 2004 e reformulada em 2007. A reformulação teve como objetivo aproximar as ações e serviços com as instituições formadoras, no sentido de promover mudanças na formação em saúde e provocar alterações nas práticas obsoletas no cuidado com a saúde, através da problematização de suas próprias práticas e do trabalho em equipe ${ }^{9}$. Essa política possibilitou a busca por reflexões e transformações a partir da educação no trabalho, convidando todos (cidadãos, usuários e profissionais de saúde) a participarem das mudanças na gestão, na sociedade e no controle social ${ }^{10}$.

Como uma estratégia de potencialização da PNEPS, foi utilizada a modalidade de Educação a Distância (EaD) online para qualificação profissional de forma indissociada de 
sua prática. A EaD online ou baseada na web é um processo de ensino-aprendizagem mediado por tecnologias, no qual professores e alunos estão separados espacial e/ou temporalmente ${ }^{11}$. Foi regulamentada, no Brasil, em 1996, com a sua inclusão na Lei de Diretrizes e Bases da Educação (LDB) ${ }^{12}$.

Essa modalidade educacional busca recursos e formas para facilitar e promover aprendizagem por meio de estratégias que incentivem participação, interação, pesquisa, debate, diálogo e, especialmente, colaboração, cooperação e compartilhamento de pensamentos, ideias e soluções para a aprendizagem ${ }^{13}$. Dessa maneira, a EaD online tornouse uma estratégia para alcançar o maior número de trabalhadores da saúde, devido à possibilidade de democratizar o conhecimento em todo o território brasileiro ${ }^{14}$. Além da popularização e expansão do acesso às tecnologias de informação e de comunicação ${ }^{15}$, trouxe também uma maior flexibilidade e autonomia no processo de aprendizagem.

Um curso com EaD online pode ser mediado (interação aluno e professor) ou autoinstrucional (aprendizado autônomo). Num curso com essa primeira modalidade, o aluno/profissional constrói a aprendizagem a partir do material disponibilizado, com acompanhamento pedagógico a distância por professores ou facilitadores ${ }^{16}$.

$\mathrm{Na}$ modalidade do curso autoinstrucional, as afirmações de que na EaD online, de acordo com o estudo de Gava et al. ${ }^{17}$, deve haver um planejamento bem cuidadoso antes de ser publicado em ambientes virtuais precisam ser consideradas. Todo planejamento necessita de organização e prazos estabelecidos, o que implica na preparação do material didático em prol do perfil do público-alvo.

Junges et al. ${ }^{18}$ realizaram um estudo em que enfatizam a importância do planejamento como instrumento norteador para a construção de um curso empregando EaD online, com qualidade. Corroborando com os autores citados, Santiago et al. ${ }^{19}$ fizeram um estudo afirmando que em Educação a Distância $(\mathrm{EaD})$ online, o planejamento é precedente à aplicação do curso e/ou disciplina, através do trabalho da equipe envolvida na elaboração. Fazer o delineamento de todas as etapas é uma atividade indispensável para alcançar o êxito de qualquer modalidade de curso (EaD online ou presencial).

Uma das formas de planejar um curso com EaD online é a utilização do Modelo de Desenho Instrucional (DI) chamado ADDIE (Analysis, Design, Development, Implementation and Evaluation) que é um dos mais utilizado por designers educacionais para a construção dos projetos de cursos. As fases que compõem esse modelo estão classificadas em dois momentos maiores denominados: Concepção e Execução. A Concepção compreende as 
fases da análise, desenho e desenvolvimento e Execução, as fases da implementação e avaliação ${ }^{17}$.

A utilização do modelo ADDIE permite uma visão geral do processo de elaboração do curso e das correções necessárias para garantir a sua efetividade e o alcance do objetivo. Nesse contexto, são cinco as fases do desenho instrucional: análise, desenho, desenvolvimento, implementação e avaliação ${ }^{20}$ (Figura 1).

Figura 1: Modelo ADDIE e as cinco fases com seus objetivos específicos.

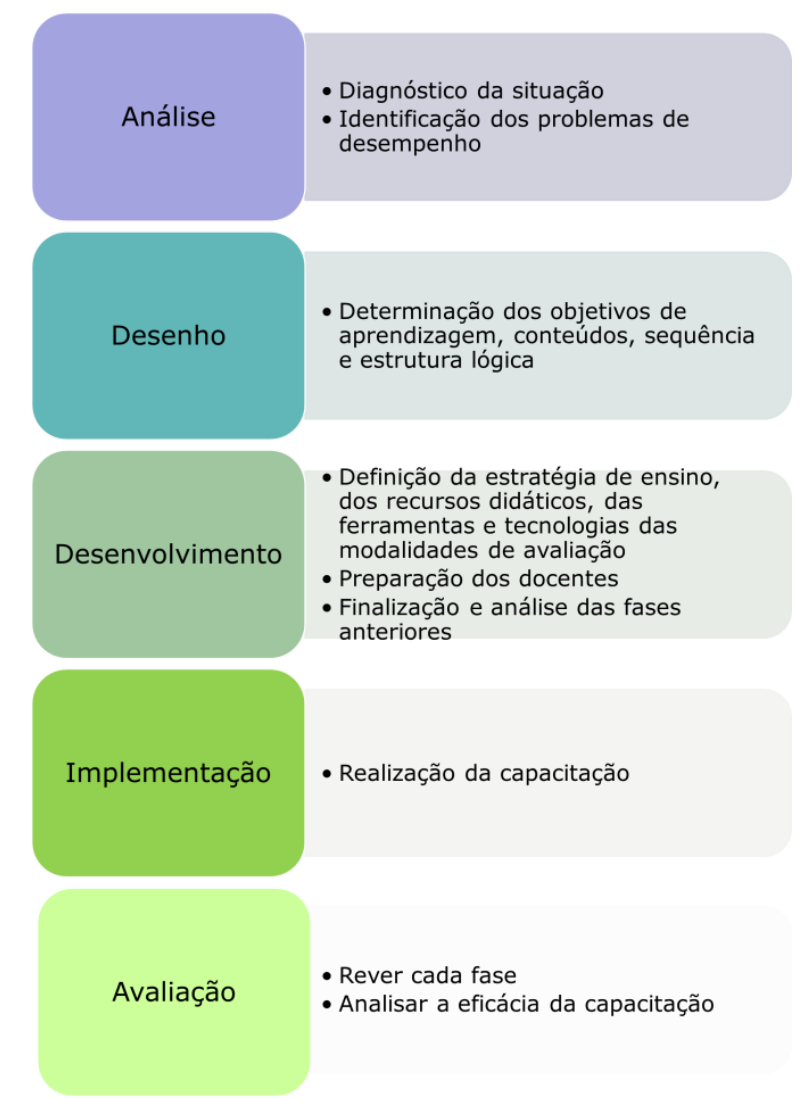

Fonte: Os autores

O planejamento do presente estudo foi norteado pelos resultados obtidos por dois trabalhos que executaram a fase de Análise ${ }^{21}$ e Desenho ${ }^{22}$ do Modelo ADDIE. 0 estudo que executou a fase de Análise foi de abordagem qualitativa através de roteiro de entrevista semiestruturada com sete cirurgiões-dentistas da atenção primária em que foram investigados o conhecimento e as vivências do profissional sobre o tema ${ }^{21}$. Já o trabalho que realizou a fase do Desenho foi conduzido por uma pesquisa on-line com especialistas de três centros de referências no cuidado dos pacientes com anomalias craniofaciais que resultou nos conteúdos e competências a serem trabalhadas durante o curso ${ }^{22}$. 
Diante disso, o presente estudo teve como objetivo compartilhar a experiência da terceira fase do Modelo ADDIE, descrevendo a experiência de desenvolvimento de um protótipo de curso educacional sobre anomalias craniofaciais para cirurgiões-dentistas da atenção primária, selecionando os melhores recursos didáticos e midiáticos capazes de proporcionar maior efetividade no aprendizado, visando mudança no processo de trabalho na atenção a pacientes com anomalia craniofacial.

\section{Métodos}

O estudo caracterizou-se como descritivo, com desenvolvimento metodológico referente ao processo de desenvolvimento de um curso na modalidade a distância, utilizando o Desenho Instrucional ADDIE ${ }^{23}$. Trata-se de um subproduto do Programa de Teleducação do Centro de Atenção aos Defeitos da Face do Instituto de Medicina integral Prof. Fernando Figueira (CADEFI/IMIP), elaborado por uma das pesquisadoras desse estudo. Esse programa tem a parceria do NTES (Núcleo de Telessaúde) do IMIP para o desenvolvimento dos recursos no ambiente virtual. Esse foi um trabalho de conclusão do Programa de Residência de Saúde Coletiva da Secretaria de Saúde do Recife com estágio no grupo de pesquisa do CADEFI/IMIP.

Na fase de Desenvolvimento do modelo ADDIE, ocorreu a elaboração do protótipo do curso em EaD online autoinstrucional (assíncrono). O curso desenvolvido por esse estudo é destinado para a população de cirurgiões-dentistas da atenção primária, porém outros profissionais odontólogos de outros níveis de atenção poderão realizá-lo para melhoria da sua prática, bem como estudantes de graduação. Foi conduzido um levantamento bibliográfico para seleção dos melhores recursos didáticos para construção do curso. As fases de implementação e avaliação serão realizadas posteriormente em outros trabalhos.

Dois autores do curso realizaram formação pedagógica para conteudistas em EaD e foram responsáveis pela sua revisão. Por se tratar de um trabalho de conclusão de residência, o curso foi submetido a banca avaliadora com profissionais experientes na temática.

Esta pesquisa foi submetida à Plataforma Brasil para apreciação Comitê de Ética em Pesquisa (Parecer n 3.226.936 e CAAE: 07931818.1.0000.5201), atendendo plenamente à resolução $n^{0} 510 / 2016^{24}$. 


\section{Resultados}

O desenvolvimento da proposta do curso resultou em dois produtos: o plano de ensino do curso e o guia do curso. Neles, foram incluídas propostas de recursos didáticos e avaliações para o curso. Utilizou-se como referencial teórico o estudo de $\mathrm{Neto}^{25}$, que tem como objetivo apresentar linguagem de padrões para estruturar o planejamento e desenvolvimento de cursos em EaD online que promovessem a aprendizagem significativa.

Primeiramente, foi elaborado um plano de ensino, utilizando o referencial teórico da taxonomia de Bloom ${ }^{26}$, que teve por objetivo ajudar no planejamento, organização de forma hierárquica dos objetivos de aprendizagem. A etapa seguinte foi a construção do guia do curso. Foram pensados recursos pedagógicos padronizados para o curso. Uma legenda foi planejada para manter o estudante ativo no processo de ensino e aprendizagem e para organizar a construção do conhecimento progressivamente (Tabela 1 - anexos).

Os autores selecionaram padrões de aprendizagem com embasamento nas estratégias cognitivas de Liebman ${ }^{27}$. As Estratégias Cognitivas utilizadas na estruturação da proposta do presente estudo foram: organizativas (aplicação das taxonomias, listagem de semelhanças e diferenças), de ensaios (perguntas e respostas, esclarecimentos, informações parafraseadas, enfatizadas, identificação de causa e efeito, que ajudam na compreensão do material pelos alunos) e de organizadores de avanço (uso de observações com conectores para outros assuntos, ênfase em algum conhecimento detalhado).

Considerando a linguagem de padrões de $\mathrm{Neto}^{25}$, as Linguagens de Padrões que se encaixaram a partir das Estratégias Cognitivas são: de Planejamento (ordenação do conteúdo), Gancho (correlação de conceitos prévios e atuais), Contextualização (imagens, vídeos para fixar melhor o conteúdo), Hierarquização (ordem dos tópicos do conteúdo, protocolos de tratamento) e Sedimentação (casos clínicos).

Para a construção do protótipo do curso, também foram utilizados os recursos das atividades do módulo: os recursos educacionais abertos, ambiente virtual de aprendizagem (AVA), artigos científicos, vídeos, imagens e animações.

A avaliação selecionada foi formativa, através de questões acerca do conteúdo, fornecendo feedbacks construtivos nas opções de resposta. 0 processo avaliativo formativo teve como objetivo direcionar a aprendizagem para a valorização dos cuidados odontológicos na atenção primária e referenciamento para centros especializados.

O curso possui uma carga horária de 7 horas, tratando-se de uma proposta autoinstrucional, portanto assíncrona, a ser disponibilizada em ambiente virtual de aprendizagem. Como recursos de aprendizagem, foram disponibilizadas referências da 
literatura científica e conteúdo multidisciplinar em modelo on-line, aberto/gratuito e massivo disponíveis.

Como objetivo geral, tem-se a construção do conhecimento dos cirurgiões-dentistas sobre anatomofisiologia do sistema estomatognático e protocolos de tratamento das principais anomalias craniofaciais, visando a compreensão da abordagem odontológica na atenção primária das principais anomalias craniofaciais por ciclos de vida. Os objetivos específicos foram produzidos nos domínios cognitivos e afetivos. No psicomotor não foi elaborado pela inviabilidade de mensurá-los nesse curso.

Elaborou-se o curso com um módulo, que contém duas unidades curriculares e tópicos. Na Unidade Curricular 1, têm-se a Anatomofisiologia do Sistema Estomatognático na Anomalia Craniofacial com 8 Tópicos: 1) Fissuras de lábio e/ou palato; 2) Sequência Pierre Robin; 3) Síndrome de Van der Woude; 4) Síndrome de Apert; 5) Síndrome de Crouzon; 6) Síndrome de Treacher Collins; 7) Displasia ectodérmica; e 8) Holoprosencefalia. Já na Unidade Curricular 2, têm-se o Cuidado odontológico nas principais anomalias craniofaciais com os tópicos: 1) Anamnese e Anestesia e 2) A importância do cirurgião-dentista da atenção primária nos protocolos de tratamento das anomalias craniofaciais.

A aplicação das Estratégias Cognitivas e das Linguagens de Padrões nesse trabalho objetivou o aperfeiçoamento da comunicação com os alunos, a fim de torná-la mais coerente, melhorando a qualidade da proposta do curso EaD. (Figura 2).

Figura 2: Recorte do Guia do curso com a linguagem de padrão de Contextualização.

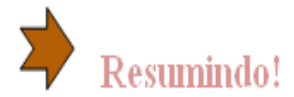

0 Centro de Estudos do Genoma Humano da Universidade de São Paulo aborda 0 assunto de maneira simples e objetiva. Vamos conferir?

Vídeo 3 - Você sabe 0 que é Síndromede Van der Woude ${ }^{23}$ ?

Disponivel em: https://www.youtube.com/watch?v=00uqJ4MPwGQ

Fonte: Os autores 


\section{Discussão}

Para o perfil do público-alvo, cirurgiões-dentistas generalistas, os autores do estudo produziram um curso claro, objetivo, com tecnologia acessível e recursos que estimulassem os profissionais no cuidado das pessoas com anomalias craniofaciais. Além disso, corroborando com a proposta de Educação Permanente no SUS ${ }^{9}$, esse produto, ao ser oferecido, pretende estimular o aluno/profissional a buscar os conhecimentos necessários para aprender a pensar criticamente e a ter autorresponsabilidade sobre sua aprendizagem no ambiente virtual.

Acredita-se que uma das vantagens do EaD online é a oportunidade de disseminação do conhecimento para profissionais de diversas áreas da saúde. Cezar et al. ${ }^{14}$ e Vargas et al. ${ }^{28}$ também corroboram com essa ideia em seus estudos e afirmaram que por meio da EaD online é possível ter uma melhor execução da Educação Permanente em Saúde. Nela, há probabilidade de discussão com situações-problema que acontecem no cotidiano do profissional, possibilitando a reflexão crítica, trocas de experiências e a cooperação. A EaD online é um modelo educacional que gera processos contínuos de acesso à informação.

Nascimento et al. ${ }^{29}$ afirmam em seu trabalho que essa modalidade de ensino é bastante promissora, possui um grande impacto na educação permanente e satisfaz os profissionais. Após a percepção da necessidade dos cirurgiões-dentistas da atenção primária no cuidado dos pacientes com anomalias craniofaciais, decidiu-se construir uma proposta de curso para orientar esses profissionais. Para a realização da fase do modelo ADDIE do presente estudo, buscou-se as estratégias didáticas e recursos midiáticos de qualidade viáveis financeiramente para a instituição. Antes de alcançar esse ideal, foi realizado um planejamento para nortear o curso empregando EaD online.

Assim como o estudo de Junges ${ }^{18}$, foram abordadas neste trabalho quatro dimensões no planejamento do curso EaD online: a dimensão conceitual (entendimento das perguntas e respostas, material didático, articulação do todo com as partes,...); a dimensão didático-pedagógica (objetivos, seleção de conteúdos, mídias, perfil do cursista/aluno, processo avaliativo); a dimensão administrativa (recursos físicos e humanos, sistema de comunicação e gestão de recursos) e a dimensão de autorregulação (avaliação do curso e da instituição). Na dimensão administrativa, firmou-se uma parceria com uma equipe multidisciplinar do NTES do IMIP, a qual será ajustada na fase de implementação do modelo ADDIE. 
Durante a construção do curso do presente estudo, preocupou-se com a estruturação dele para que o custo fosse mínimo e as questões financeiras não prejudiquem a aprendizagem do cursista, corroborando com Moreira et al. ${ }^{30}$. Ademais, quanto à elaboração e planejamento do conteúdo, estes foram pensados visando o desenvolvimento das competências do cursista, incluindo as cognitivas, aplicadas na Taxonomia de Bloom, conforme preconizado por Moreira et al. ${ }^{31}$.

Assim como em Carvalho et al. ${ }^{32}$, o conteúdo do curso foi selecionado por meio da pesquisa do referencial teórico científico sobre as anomalias craniofaciais para incluir informações confiáveis e o mais atuais possíveis. Foram encontrados materiais importantes de alguns centros sobre o tema anomalias craniofaciais.

Quanto a utilização de vídeos, artigos, imagens e animações nesse curso, a intenção foi favorecer a sedimentação do conteúdo de forma dinâmica. Nesse ponto, concordou-se com os autores Onari e Yonezawa ${ }^{33}$ e Barreiro ${ }^{34}$, que confirmaram, em seus trabalhos, que o material didático digital possui recursos e vantagens como: facilidade de duplicação, acessibilidade, possibilita atualizações do conteúdo e diferentes maneiras de interações que os materiais impressos não proporcionam.

Uma das limitações do estudo foi a dificuldade de encontrar conteúdo bibliográfico recente sobre algumas anomalias craniofaciais. Outra possível limitação é uma elevada taxa de evasão dos cursistas, devido a essa modalidade de ensino exigir autodisciplina no processo de aprendizagem. Adicionalmente, o curso ficará numa plataforma de ambiente virtual de aprendizagem, embora a intenção seja oferecê-lo gratuitamente ao ser produzido. Ele não se enquadra como um Massive Open Online Course (MOOC) que permite acesso com mais facilidade por qualquer pessoa, pois ainda não foi estabelecido se a instituição possui potencial financeiro, nem a possibilidade da existência de um fórum com mediadores de discussões. A produção de um curso online bem estruturado e aberto exige um alto custo de investimento ${ }^{35}$. Pretende-se, na fase de implantação e análise do curso, estudar o impacto desse modelo na adesão ao mesmo.

Contudo, essa pesquisa trouxe como benefício o compartilhamento da experiência de construção de curso a distância para os profissionais de saúde, cirurgiões-dentistas, que atuam na atenção primária do SUS, com a finalidade de melhorar a qualidade dos serviços aos pacientes com anomalias craniofaciais, de modo a alcançar equidade no cuidado e qualificação dos profissionais para o atendimento às necessidades desta população específica. 


\section{Conclusão}

Neste trabalho, foram utilizados referenciais teóricos que permeiam o modelo ADDIE, o tema anomalias craniofaciais e educação a distância na construção de um protótipo de um curso EaD online para cirurgiões-dentistas da atenção primária. Foi observado que o design instrucional de cursos virtuais precisa ser planejado tanto para a elaboração de conteúdos quanto para a proposta de mídias e atividades, devendo-se basear sempre no aprendizado do aluno.

Diante disso, viu-se também que outros estudos sobre a estruturação de curso em EaD precisam ser realizados. A discussão pedagógica e o compartilhamento da experiência viabilizam a elaboração de novos cursos, pois esse modelo de ensino possui um vasto e rico potencial educativo.

\section{Referências}

1. Monlleó IL. Anomalias craniofaciais, genética e saúde pública: contribuições para o reconhecimento da situação atual da assistência no Sistema Único de Saúde. Campinas: Universidade Estadual de Campinas (UNICAMP), 2004. Dissertação de Mestrado.

2. Monlleó IL, Gil-da-Silva-Lopes VL. Anomalias craniofaciais: descrição e avaliação das características gerais da atenção no Sistema Único de Saúde. Cad. Saúde Pública. Rio de Janeiro. 2006 mai; 22(5): 913-922.

3. Word Health Organization. Global strategies to reduce the health-care burden of craniofacial anomalies. Geneva: Word Health Organization.2002.

4. Freitas JAS, Neves LT, Almeida ALPF, Garib DG, Trindade-Suedam IK, Yaedú RYF, et al. Rehabilitative treatment of cleft lip and palate: experience of the Hospital for Rehabilitation of Craniofacial Anomalies/USP (HRAC/USP) - Part 1: overall aspects. J Appl Oral Sci. 2012; 20(1):9-15.

5. Murray JC. et al. Clinical and epidemiologic studies of cleft lip and palate in the Philippines. CleftPalateCraniofac. J. Lewiston. 1997 jan; 34(1):7-10.

6. Mendoza RL. Public Health Policy and Medical Missions in the Philippines: The Case of Oral-Facial Clefting. Asia-Pacific Journal of Public Health. 2009; 21(1):94103.

7. Mendes M, Silveira MM, Costa FS, Schardosim LR. Avaliação da percepção e da experiência dos cirurgiões-dentistas da rede municipal de Pelotas/RS no atendimento aos portadores de fissuras labiopalatais. RFO. Passo Fundo. 2012 mai/ago; 17(2): 196-200.

8. Almeida AMFL, Lima Chaves SCL, Santos CML, Santana SF. Atenção à pessoa com fissura labiopalatina: proposta de modelização para avaliação de centros especializados, no Brasil. Saúde em Debate. 2017; 41:156-166.

9. Brasil. Ministério da Saúde. Secretaria de Gestão do Trabalho e da Educação na Saúde. Departamento de Gestão da Educação em Saúde. A educação permanente 
entra na roda: polos de educação permanente em saúde: conceitos e caminhos a percorrer. Brasília (DF), Ministério da Saúde,2004.

10. Da Silva CT, Souto VT, Roso CC, Terra MG. Educação permanente em saúde: percepção de profissionais de uma residência multidisciplinar. Revista de Enfermagem da UFSM. 2013; 3:627-635.

11. Moran JM. O que é educação a distância. 2002. Disponível em: ww2.eca.usp.br/moran/wp-content/uploads/2013/12/dist.pdf. Acesso em: 22 de Fevereiro de 2020.

12. Zaina LAM, Ruggiero WV, Bressan G. Metodologia para acompanhamento do aluno através da web. Revista brasileira de informática na educação. 2004; 1:12-20.

13. Gottardi ML. A autonomia na aprendizagem em educação a distância: competência a ser desenvolvida pelo aluno. Associação Brasileira de Educação à Distância. Faculdade da Serra Gaúcha (FSG). 2015;14.

14. Cezar DM, Costa MR, Magalhães CR. Educação a distância como estratégia para a educação permanente em saúde? Em Rede - Revista de Educação a Distância. 2017;4(1).

15. Brasil. Ministério da Educação. Referenciais de Qualidade para Educação Superior a Distância. 2007. Disponível em:

http://portal.mec.gov.br/seed/arquivos/pdf/referenciaisead.pdf . Acesso em: 22 de Fevereiro de 2020.

16. Ribeiro MAS, Lopes MHBM. Desenvolvimento, aplicação e avaliação de um curso a distância sobre tratamento de feridas. Rev Latino-Am Enfermagem. 2007; 14:77-84.

17. Gava TBS; Nobre IAM; Sondermann DVC. O modelo ADDIE na construção colaborativa de disciplinas a distância. Informática na Educação: teoria e prática. Porto Alegre. 2014 jan/jun; 17(1):111-124.

18. Junges KS, Povaluk M, Santos VS. O planejamento como elemento norteador da qualidade do processo de ensino e aprendizagem na educação a distância. PUCPR. 2009.

19. Santiago LML, Ramos RF, Joye CR. Sistema de gestão e planejamento de conteúdos didáticos digitais para EaD . Braz. J. of Develop. Curitiba. 2019 mar; 5(3): 22192234.

20. Filatro A. Design instrucional na prática. São Paulo. Pearson Education do Brasil.2008.

21. Coutinho EP. Estratégia Educacional para Cirurgiões-Dentistas da Atenção Primária: Fase de Análise do Modelo ADDIE. Recife: Secretaria de Saúde (SESAU-PE), 2019. Trabalho de Conclusão da Residência em Odontologia em Saúde Coletiva.

22. Cavalcante EC. Estratégia Educacional para Cirurgiões-Dentistas da Atenção Primária: Fase de Desenho do Modelo ADDIE. Recife: Secretaria de Saúde (SESAUPE), 2019. Trabalho de Conclusão da Residência em Odontologia em Saúde Coletiva.

23. Oliveira JM. Subsídios para Formulação de um Curso de Desenho Instrucional. Brasília. Enap.2011.

24. Ministério da Saúde. Resolução n 510, de 7 de Abril de 2016. O Plenário do Conselho Nacional de Saúde em sua Quinquagésima Nona Reunião Extraordinária, realizada nos dias 06 e 07 de abril de 2016, no uso de suas competências regimentais e atribuições conferidas pela Lei n o 8.080, de 19 de setembro de 1990, pela Lei n o 8.142, de 28 de dezembro de 1990, pelo Decreto n o 5.839, de 11 de julho de 2006. Disponível em: http://bvsms.saude.gov.br/bvs/saudelegis/cns/2016/res0510_07_04_2016.html. Acesso em: 02 de nov. de 2018. 
25. Neto AT, Anacleto JC, Neris VPA. Padrões para Apoiar o Projeto de Material Instrucional para EAD. Departamento de Computação - Universidade Federal de São Carlos (UFSCar), São Carlos - SP - Brasil. 2005.

26. Bloom BS. Taxonomia de objetivos educacionais, Manual: O domínio cognitivo. David McKay, Nova lorque. 1956; 1:262.

27. Liebman, J. Teaching Operations Research: Lessons from Cognitive Psychology. Interfaces. 1998; 28 (2):104-110.

28. Vargas FMA, Trindade MCN, Gouveia GDA, Farias MR. A Educação a Distância na Qualificação de Profissionais para o Sistema Único De Saúde: metaestudo. Trabalho, Educação e Saúde. Rio de Janeiro. 2016 dez; 14(3):849-870.

29. Nascimento CMB, Lima MLLT, Sousa FOS, Novaes MA, Galdino DR, Silva ÉCH, Leitão GGS, Silva TPS. Telefonoaudiologia como estratégia de educação permanente na atenção primária à saúde no Estado de Pernambuco. Revista CEFAC. São Paulo. 2017 Jun; 19(3): 371-380.

30. Moreira MM, Araújo ACU, Torres ALMM, Joye CR, Neto HB. Ensaio teórico sobre o Design Instrucional Contextualizado e as Estratégias Didáticas na Elaboração de Material Didático para EaD Online. Revista de Educação a Distância- Em Rede. 2019; 6(1).

31. Moreira MM, Araújo ACU, Torres ALMM, Joye CR, Neto HB. Ensaio teórico sobre elaboração de material didático de matemática para EaD online: estratégias didáticas em foco. In: XVIII Congresso de História da Educação do Ceará, 2018, Sobral. Tecnologias da Educação: passado, presente e futuro. Fortaleza. UFC. 2018.

32. Carvalho LV, Carvalho AT, Áfio ACE, Silva ASR, Silva MG, Pagliuca LMF. Construção de tecnologia assistiva na modalidade curso online para cegos sobre hipertensão arterial. Rev Bras Enferm [Internet]. 2018; 71(4):2085-91.

33. Onari DY, Yonezawa WM. O papel do design na produção de jogos digitais educacionais para o ensino de ciências. In: Coutinho, S. G.; Moura, M.; Campello, S. B.; Cadena, R. A.; Almeida, S. (eds.). Proceedings of the 6th Information Design International Conference, 5th InfoDesign, 6th Congic [= Blucher Design Proceedings]. São Paulo: Blucher. 2014; 1(2).

34. Barreiro RMC. Um Breve Panorama sobre o Design Instrucional. Rev. EaD em Foco. 2016; 6(2).

35. Hood N, Littlejohn A. MOOC Quality: the need for new measures. Journal of Learning for Development - JL4D. 2016; 3(3):28-42. 


\section{Anexos}

Tabela 1. Tabela com as unidades, tópicos, objetivos de aprendizagem, conteúdo e recursos didáticos.

\begin{tabular}{|c|c|c|c|c|}
\hline Unidade & Tópicos & $\begin{array}{c}\text { Objetivo de } \\
\text { Aprendizagem }\end{array}$ & Conteúdo & $\begin{array}{l}\text { Recursos } \\
\text { Didáticos }\end{array}$ \\
\hline \multirow{3}{*}{$\begin{array}{c}1 \text { - } \\
\text { Anatomofisiologia } \\
\text { do Sistema } \\
\text { Estomatognático } \\
\text { na Anomalia } \\
\text { Craniofacial }\end{array}$} & $\begin{array}{l}1 \text { - Fissuras de } \\
\text { lábio e/ou palato }\end{array}$ & $\begin{array}{l}\text { Conhecer } \\
\text { anatomofisiologia do } \\
\text { sistema } \\
\text { estomatognático no } \\
\text { paciente com Fissuras } \\
\text { de lábio e/ou palato. } \\
\text { Diferenciar o conceito } \\
\text { de paciente com } \\
\text { anomalia craniofacial } \\
\text { de paciente com } \\
\text { deficiência no âmbito da } \\
\text { oferta de tratamento } \\
\text { odontológico no SUS. }\end{array}$ & $\begin{array}{l}\text { Definição de } \\
\text { anomalia } \\
\text { craniofacial nos } \\
\text { serviços } \\
\text { odontológicos } \\
\text { do SUS. }\end{array}$ & $\begin{array}{l}\text { Conceito } \\
\text { Clique aqui } \\
\text { (vídeo) } \\
\text { Atenção } \\
\text { Cirurgião- } \\
\text { dentista! } \\
\text { Imagem }\end{array}$ \\
\hline & $\begin{array}{l}2 \text { - Sequência } \\
\text { Pierre Robin }\end{array}$ & $\begin{array}{l}\text { Conhecer a } \\
\text { anatomofisiologia do } \\
\text { sistemaestomatognátic } \\
\text { o no paciente com } \\
\text { Sequência Pierre Robin }\end{array}$ & $\begin{array}{l}\text { Anamnese de } \\
\text { pacientes com } \\
\text { anomalias } \\
\text { craniofaciais. }\end{array}$ & $\begin{array}{l}\text { Conceito } \\
\text { Palavra } \\
\text { destacada } \\
\text { (sublinhada) } \\
\text { Imagens } \\
\text { S Saiba mais! } \\
\text { com Hiperlink } \\
\text { Clique aqui }\end{array}$ \\
\hline & & & $\begin{array}{l}\text { Anomalias } \\
\text { dentárias de } \\
\text { forma, número } \\
\text { e posição, } \\
\text { defeito ósseo } \\
\text { alveolar, atresia } \\
\text { das bases } \\
\text { ósseas, } \\
\text { principalmente } \\
\text { maxilar, } \\
\text { discrepância } \\
\text { sagital das } \\
\text { bases ósseas, } \\
\text { entre outras; } \\
\text { Mastigação, } \\
\text { deglutição, } \\
\text { respiração e } \\
\text { fonação; }\end{array}$ & \\
\hline
\end{tabular}




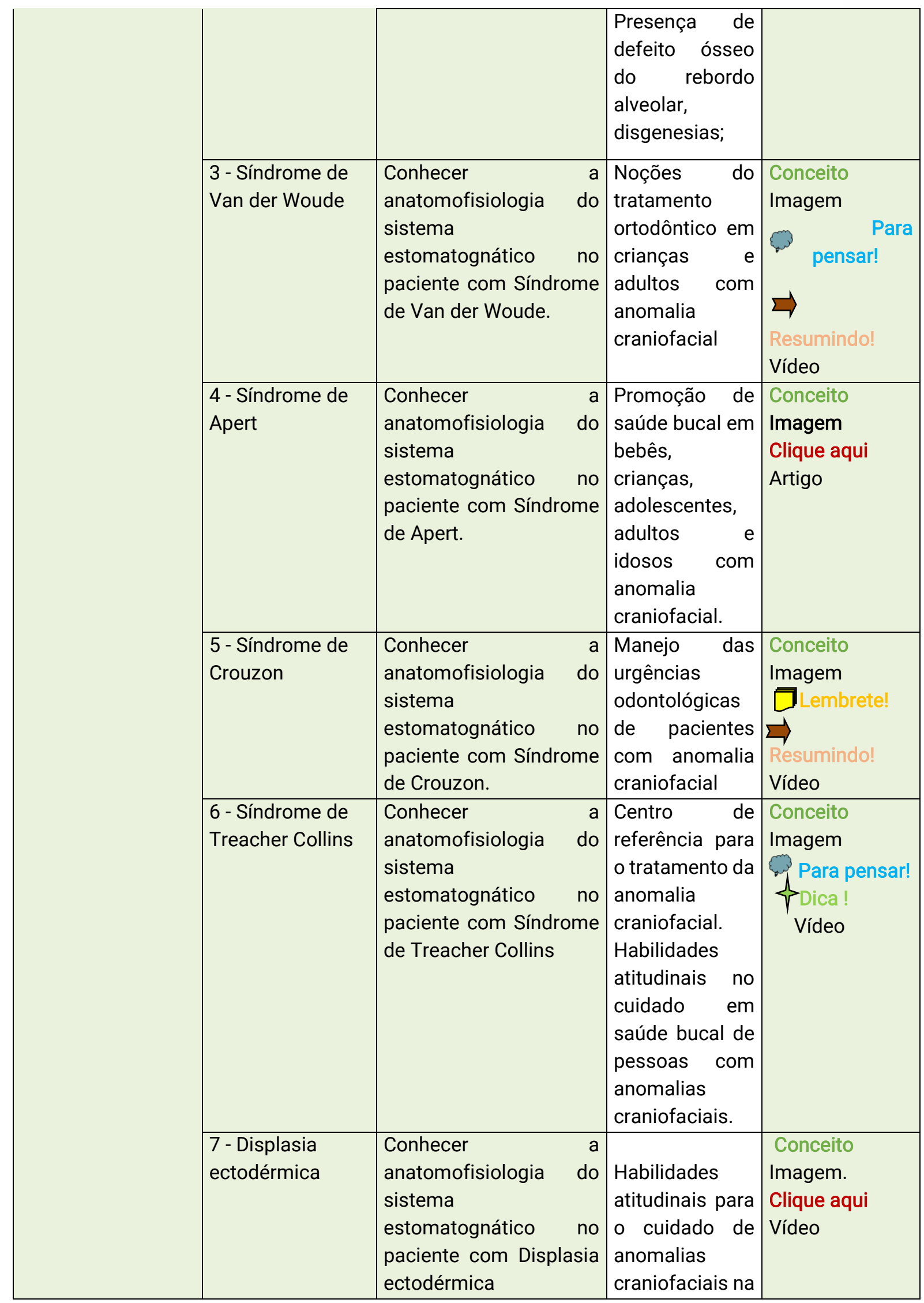


16

\begin{tabular}{|c|c|c|c|c|}
\hline & $\begin{array}{l}8 \text { - } \\
\text { Holoprosencefali } \\
\text { a }\end{array}$ & $\begin{array}{lr}\begin{array}{lr}\text { Conhecer } \\
\text { anatomofisiologia }\end{array} & \text { do } \\
\text { sistema } & \\
\text { estomatognático } & \text { no } \\
\text { paciente } & \text { com } \\
\text { Holoprosencefalia } & \end{array}$ & $\begin{array}{l}\text { rede de atenção } \\
\text { à saúde }\end{array}$ & $\begin{array}{l}\text { Conceito } \\
\text { Clique aqui } \\
\text { Imagem } \\
\text { Vídeo } \\
\square \text { Lembrete! }\end{array}$ \\
\hline \multirow{2}{*}{$\begin{array}{l}\text { 2- Cuidado } \\
\text { odontológico nas } \\
\text { principais } \\
\text { anomalias } \\
\text { craniofaciais }\end{array}$} & $\begin{array}{l}1 \text { - Anamnese e } \\
\text { Anestesia }\end{array}$ & $\begin{array}{lr}\text { Conhecer as alterações } \\
\text { anatomofisiológicas } \\
\text { das anomalias } \\
\text { craniofaciais } \\
\text { realizar para } \\
\text { anestésicas } \\
\text { odontológicas. }\end{array}$ & & $\begin{array}{l}\text { [?] Fique } \\
\text { atento! }\end{array}$ \\
\hline & $\begin{array}{l}2 \text { - A importância } \\
\text { do cirurgião- } \\
\text { dentista da } \\
\text { atenção primária } \\
\text { nos protocolos de } \\
\text { tratamento das } \\
\text { anomalias } \\
\text { craniofaciais. }\end{array}$ & $\begin{array}{lr}\text { Compreender } & \text { as } \\
\text { intervenções } & \text { e } \\
\text { protocolos } & \text { de } \\
\text { tratamento } & \text { na } \\
\text { reabilitação } & \text { das } \\
\text { anomalias } & \end{array}$ & & $\begin{array}{l}\text { Clique aqui } \\
\text { Vídeo } \\
\text { Imagem. } \\
\text { Atenção } \\
\text { Cirurgião- } \\
\text { dentista! } \\
\text { Não } \\
\text { esqueça! } \\
\text { ك Saiba mais! }\end{array}$ \\
\hline
\end{tabular}

Fonte: Os autores. 